\title{
Changes in the corticosteroid concentrations of plasma from single and twin fetuses during the last 3 weeks of pregnancy in sheep
}

\author{
D. J. Mellor, I. C. Matheson and J. Small \\ Moredun Research Institute, Gilmerton, Edinburgh, U.K.
}

The apparently vital role of the fetal adrenal glands in the initiation of parturition in sheep has received a great deal of attention, particularly with regard to possible causes and consequences of the marked rise in the corticosteroid concentrations of fetal plasma which precedes birth (see Challis \& Thorburn, 1975). However, little or no attention has been given to the possibility that the time course of the terminal corticosteroid increase might be different in single, first-born twin and second-born twin fetuses. In a total of five bicornuate twin pregnancies we found that the $\mathrm{pH}$ of fetal urine began to decrease before parturition at least 2 days earlier in the first fetus to be born than in the second-born littermate(Mellor \& Slater, 1972a, and unpublished). If, as we suggested, these decreases in urinary pH were due to the terminal corticosteroid rise, these observations would indicate that the corticosteroid patterns in twin littermates might be different. The purpose of the present study was to examine this possibility.

A total of 16 4-year-old Scottish Blackface ewes (45-60 kg), seven carrying twins, were brought indoors 20-30 days after mating. The day of mating, indicated by rump dye marks, was taken as Day 0 of pregnancy. The preoperative training and general maintenance procedures were as described by Pearson \& Mellor (1976) and Mellor \& Slater (1972b), respectively. At 108-114 days of gestation a catheter was inserted by the method of Mellor \& Matheson (1975) into an umbilical artery and vein of 23 fetuses. Maternal jugular blood and fetal blood were sampled according to the schedule outlined by Mellor, Matheson, Small \& Wright (1976). Blood was obtained until term from all fetuses and parturition occurred without complications in all ewes. In the 7 sets of twins, which all had a bicornuate distribution in the uterus, the uterine horn from which the first-born fetus had come was ascertained manually before the birth of the second. The birthweights and growth rates during the first 6 weeks of all lambs were similar to those reported by Mellor \& Slater (1971).

The total corticosteroid concentrations in heparinized plasma were measured using a modified competitive protein-binding assay based on those described by Murphy (1967) and Bassett \& Hinks (1969). Standard dilutions (5-70 ng/ml) of cortisol (Koch-Light Laboratories) were prepared and made up in corticosteroid-free ovine plasma; blank radioactive counts were always $<5 \%$ of the total counts. The minimum detectable concentration was $1 \mathrm{ng} / \mathrm{ml}$, and each unknown sample was analysed in triplicate. The within- and between-assay coefficients of variation were never greater than $6.7 \%$. Samples obtained within 14 days of operation were not analysed. Mean ( \pm S.E.M.) values for each day during the last 3 weeks of pregnancy (Days - 21 to 0 ) were calculated for the 9 single fetuses which were born between 144 and 150 days of gestation and for the first- and second-born fetuses in the 7 sets of twins which were born between 147 and 157 days (Table 1). The results of split-plot analyses of these data were the same whether the absolute concentrations or their natural logarithms (In) were used, and each analysis was validated by the method of Rowell \& Walters (1976). There were no significant differences between the concentrations in the three groups between Days -21 and -9 , or between singletons and first-born twins between Days $\mathbf{- 8}$ and 0 , but singletons and first-born twins both had significantly higher $(P<0.05)$ concentrations than second-born twins between Days -8 and 0 . Between Days -21 and 0 the interactions of concentration with time (i.e. the patterns of corticosteroid changes) in singletons and first-born twins did not differ significantly, but both were significantly different $(P<0.05)$ from the corresponding concentration-time interaction in second-born twins. Maternal plasma concentrations $(5-15 \mathrm{ng} / \mathrm{ml})$ remained relatively constant in each animal between Days -21 and -1 . 
Table 1. Changes in the mean ( \pm S.E.M.) plasma corticosteroid concentrations of fetal sheep during the last 3 weeks of pregnancy in 9 single fetuses $(S)$ and in the first-born $\left(T_{1}\right)$ and second-born $\left(T_{2}\right)$ fetus in 7 sets of twins

\begin{tabular}{|c|c|c|c|c|c|c|c|}
\hline Day & $\mathbf{S}$ & $T_{1}$ & $\mathrm{~T}_{2}$ & Day & $\mathbf{S}$ & $\mathrm{T}_{1}$ & $\mathrm{~T}_{2}$ \\
\hline-21 & $5.8 \pm 0.6$ & $5 \cdot 5 \pm 0.8$ & $6.4 \pm 0.5$ & -10 & $11 \pm 1 \cdot 1$ & $13 \pm 1 \cdot 2$ & $12 \pm 1 \cdot 2$ \\
\hline-20 & $6.2 \pm 0.6$ & $5.4 \pm 0.7$ & $6.7 \pm 0.4$ & -9 & $12 \pm 1 \cdot 4$ & $15 \pm 1 \cdot 3$ & $15 \pm 1.6$ \\
\hline-19 & $6.2 \pm 0.8$ & $5.6 \pm 0.7$ & $6.4 \pm 0.6$ & -8 & $15 \pm 1.9$ & $18 \pm 1 \cdot 7$ & $13 \pm 1.6$ \\
\hline-18 & $6.2 \pm 0.8$ & $6.1 \pm 0.5$ & $6.9 \pm 0.7$ & -7 & $20 \pm 3.0$ & $20 \pm 2 \cdot 2$ & $17 \pm 1.6$ \\
\hline-17 & $6.8 \pm 0.9$ & $6.7 \pm 0.9$ & $6.2 \pm 0.8$ & -6 & $23 \pm 3 \cdot 0$ & $29 \pm 5.5$ & $20 \pm 2.5$ \\
\hline-16 & $7 \cdot 3 \pm 0.6$ & $7 \cdot 5 \pm 1 \cdot 0$ & $7 \cdot 8 \pm 1 \cdot 0$ & -5 & $28 \pm 4 \cdot 0$ & $37 \pm 4 \cdot 1$ & $25 \pm 2 \cdot 7$ \\
\hline-15 & $7.4 \pm 0.7$ & $7.8 \pm 0.7$ & $8.7 \pm 0.9$ & -4 & $35 \pm 4 \cdot 1$ & $36 \pm 4 \cdot 7$ & $27 \pm 2.9$ \\
\hline-14 & $7.6 \pm 0.7$ & $7.5 \pm 0.7$ & $8.6 \pm 1.0$ & -3 & $49 \pm 6 \cdot 3$ & $49 \pm 4 \cdot 4$ & $38 \pm 6.0$ \\
\hline-13 & $7.7 \pm 0.9$ & $11 \pm 1 \cdot 0$ & $8.6 \pm 0.6$ & -2 & $57 \pm 6.2$ & $66 \pm 7 \cdot 5$ & $46 \pm 6.0$ \\
\hline-12 & $8 \cdot 8 \pm 1 \cdot 1$ & $12 \pm 1 \cdot 3$ & $11 \pm 1 \cdot 2$ & -1 & $80 \pm 9 \cdot 4$ & $105 \pm 13$ & $67 \pm 10$ \\
\hline-11 & $11 \pm 1 \cdot 3$ & $10 \pm 1 \cdot 0$ & $10 \pm 0.9$ & $0^{*}$ & $146 \pm 12$ & $123 \pm 14$ & $111 \pm 8 \cdot 7$ \\
\hline
\end{tabular}

* Samples were taken during the second stage of labour.

The time at which the terminal corticosteroid rise began in each fetus was determined by reference to In-transformed data which were smoothed by taking four-point moving averages. The data so treated showed a distinct point of inflection in every fetus, and the onset of the rise was taken as 1 day nearer to term than the point of inflection. The rises began at Days $-13.0 \pm 0.8(9),-13.4 \pm 0.8(7)$ and $-10.6 \pm 0.7(7)$ in the single, first-born twin and second-born twin fetuses, respectively. The difference between the values for singletons and first-born twins was not significant, but both were significantly different $(P<0.05)$ from the value for second-born twins. The time of onset of the rise was not significantly correlated with gestational period in any group.

It is evident that the terminal corticosteroid rises in singletons and first-born twins were similar and that the corticosteroid pattern in second-born twins was distinct. The source of the difference between first- and second-born twins remains unknown since the two types were approximately homogeneous with respect to sex ratio and the horn of the uterus occupied, and there was no consistent or significant difference between their birthweights. However, the earlier rise (by $2.9 \pm 0.8$ days) in the plasma corticosteroid concentrations in first-born than in second-born twins observed here does confirm the prediction of Mellor \& Slater (1972a). In addition, the different corticosteroid patterns are the likely cause of the development of greater myometrial contractions in the horn occupied by the first fetus to be born when there is one twin in each horn (Hindson, Schofield \& Turner, 1968), because myometrial sensitivity to contractile stimuli increases as an indirect result of the terminal corticosteroid rise (Liggins, Fairclough, Grieves, Kendall \& Knox, 1973; Challis \& Thorburn, 1975). However, the bicornuate twin pregnancy is probably a special case because both fetuses would have equal access to the cervix. In unicornuate twin pregnancies and in triplet pregnancies, the fetus adjacent to the cervix would invariably be born first, but would not necessarily show the first corticosteroid rise.

We are grateful to all who assisted, particularly Dr A. C. Field, Dr D. J. Lockwood, Mr M. McLauchlan and Mr A. Wilson.

\section{References}

BassetT, J.M. \& Hinks, N.T. (1969) Micro-determination of corticosteroids in ovine peripheral plasma; effects of venipuncture, corticotrophin, insulin and glucose. $J$. Endocr. 44, 387-403.

Challis, J.R.G. \& Thorburn, G.D. (1975) Prenatal endocrine function and the initiation of parturition. Br. med. Bull. 31, 57-62.

Hindson, J.C., SCHOFIELD, B.M. \& TURner, C.B. (1968) Parturient pressures in the ovine uterus. J. Physiol., Lond. 195, 19-28.
Liggins, G.C., Fairclough, R.J., Grieves, S.A., Kendall, J.Z. \& KNOX, B.S. (1973) The mechanism of initiation of parturition in the ewe. Recent Prog. Horm. Res. 29, 111-150.

Mellor, D.J. \& Matheson, I.C. (1975) Chronic catheterisation of the aorta and umbilical vessels of fetal sheep. Res. vet. Sci. 18, 221-223.

Mellor, D.J. \& Slater, J.S. (1971) Daily changes in amniotic and allantoic fluid during the last three months of pregnancy in conscious, unstressed ewes, 
with catheters in their foetal fluid sacs. J. Physiol., Lond. 217, 573-604.

Mellor, D.J. \& Slater, J.S. (1972a) Preparturient changes in the $\mathrm{pH}$ of urine from chronically catheterized foetal sheep. Res. vet. Sci. 13, 89-90.

Mellor, D.J. \& SLATER, J. S. (1972b) Daily changes in fetal urine and relationships with amniotic and allantoic fluid and maternal plasma during the last two months of pregnancy in conscious, unstressed ewes with chronically implanted catheters. J. Physiol., Lond. 227, 503-525.

Mellor, D.J., Matheson, I.C., Small, J. \& Wright, H. (1976) Plasma thyroxine concentrations in ewes and their fetuses during the last six weeks of pregnancy. Res. vet. Sci. 21, 102-103.
MURPHY, B.E.P. (1967) Some studies of the proteinbinding of steroids and their application to the routine micro- and ultramicro-measurement of various steroids in body fluids by competitive proteinbinding radioassay. J. clin. Endocr. Metab. 27, 973990.

Pearson, R.A. \& Mellor, D.J. (1976) Some behavioural and physiological changes in pregnant goats and sheep during adaptation to laboratory conditions. Res. vet. Sci. 20, 215217.

Rowell, J.G. \& Walters, D.E. (1976) Analysing data with repeated observations on each experimental unit. J. agric. Sci., Camb. 87, 423432.

Received 12 January 1977 